\title{
Maternal foetal attachment and perceived stress during pregnancy
}

\author{
Akankshi Srivastava*, Pallavi Bhatnagar \\ Department of Psychology, University of Lucknow, Lucknow, Uttar Pradesh, India \\ Received: 06 July 2019 \\ Accepted: 05 August 2019 \\ *Correspondence: \\ Akankshi Srivastava, \\ E-mail: akankshisrivastava@yahoo.co.in \\ Copyright: (C) the author(s), publisher and licensee Medip Academy. This is an open-access article distributed under \\ the terms of the Creative Commons Attribution Non-Commercial License, which permits unrestricted non-commercial \\ use, distribution, and reproduction in any medium, provided the original work is properly cited.
}

\begin{abstract}
Background: In recent years, the construct of maternal foetal attachment (MFA) has gained a lot of attention. The significance of the bond between the mother and her child she is carrying has led researchers to study how the expecting woman's feelings towards the unborn child, have long lasting effects on the child. Although several psychological factors, such as maternal anxiety, attitude towards the baby and access to foetal imaging procedures, have been established to significantly influence a mother's attachment to her foetus, there seems to be a paucity of empirical work on the relationship between maternal stress during pregnancy and maternal foetal attachment. The present research is a step in this direction and purports to explore this relationship.

Methods: The study explored the relationship between MFA and stress using the maternal foetal attachment scale by Cranley and the stress scale of the ADSS by Bhatnagar et al. The sample consisted of 53 pregnant women with a mean age of 26.4 .

Results: The results suggest a significant negative relationship between stress and MFA, $r=-0.55(p<0.01)$. Stress also showed a negative correlation with the subscales of MFAS, with highly stressed women reporting lower levels of selfgiving behavior, fewer thoughts of role taking and lesser interactive behavior with the foetus.

Conclusions: High stress during pregnancy could impede the formation of a strong bond between the expecting woman and her foetus. Thus the best practices during pregnancy should aim to reduce stress and encourage maternal foetal interaction.
\end{abstract}

Keywords: Garbhsanskar, Maternal foetal attachment, Maternal stress, Pregnancy

\section{INTRODUCTION}

Ever since the $20^{\text {th }}$ century, when John Bowlby propounded his attachment theory, the construct of attachment has been recognized as a significant determinant in a child's development. Bowlby gave special importance to the bond that exists between the mother and her biological child. ${ }^{1}$ According to Bowlby, this attachment bond that grows out of a caring and sensitive relationship between the mother and her baby, is crucial not only for the child's survival, but also serves as a template for all future social, emotional and cognitive experiences. $^{2}$
Even during pregnancy, the mother is the baby's primary source of contact with the outer world. As has been observed by Stainton, the foetus reacts to the mother's immediate physical and psychological environment by abdominal stroking, kicking and moving. ${ }^{3}$ This reciprocal relationship is understood to lead to the formation of a bond, of attunement and security, that the mother develops with her child much before he or she is born. A mother's state of intense devastation on losing her baby during birth is proof to how similar this prenatal bond is to the attachment relationship between a mother and her infant. Observations of such incidents along with the conclusions about the significance of the early post- 
partum contact between the mother and her new born led to the emergence of the construct of maternal foetal attachment or MFA. ${ }^{4,5}$

Rubin, with her work on maternal role taking, paved the way for research on MFA, she stated that the immediate bond between the mother and her new born infant existed as a result of prenatal processes. ${ }^{6}$ Cranley, in her pioneering work on MFA, defined maternal foetal attachment as "the extent to which women engage in behaviours that represent an affiliation and interaction with their unborn child."7

While Cranley's definition of the construct is focused more on the behavioural aspect of the attachment relationship, later researchers looked at it as the emotional tie which normally develops between the pregnant parent and her unborn child. ${ }^{8}$ Muller posited maternal foetal attachment as "the unique, affectionate relationship that develops between a woman and her fetus". 9

The well known psychoanalyst, Donald Winnicott, labelled this psychological condition, as a primary maternal preoccupation, that mothers experience during the late period of their pregnancy. ${ }^{10}$ The state of primary maternal preoccupation can be understood as a sort of temporary obsessive-compulsive anxiety phenomenon that develops late in pregnancy, peaks within a few days after delivery, and, in most women, slowly declines during the first few months postpartum. ${ }^{11,12}$ According to Winnicott, such a preoccupation on the part of the mother is healthy as it helps a woman transition smoothly into the maternal role. ${ }^{10}$

Maternal foetal attachment proves to be an important construct as it is a good predictor of postnatal mother infant attachment. Studies have shown that mothers who score higher on facets of MFA are more likely to indulge in responsive and stimulating interaction with their infants. ${ }^{13}$ Evidence also indicates a positive relation between prenatal foetal attachment and foetal health. ${ }^{14}$ This association can be explained in light of the mother's health practices. Women who report higher attachment to their unborn child are more likely to indulge in healthier behaviour during their pregnancy. ${ }^{15,16}$

Considering MFA has proven to be such an important predictor of the physical as well as emotional well being of the mother and the child, it is imperative to study the factors that could influence the mother's attachment. Various studies across cultures have indicated how different psychological variables, such as anxiety, depression, psychological well-being, etc., are associated with maternal foetal attachment. ${ }^{15,17,18}$

Another psychological variable, namely stress, could prove as a significant predictor of the type of attachment bond the mother develops towards the foetus. Pregnancy could be a stress inducing period for a woman as having a baby could bring along with it an imbalance in the physical, psychological, social and economic demands and resources. ${ }^{19}$ Various factors such as an unplanned pregnancy, lack of social support, societal pressures, difficult working conditions, and or deficiency in economic resources might serve as stress inducers for an expecting woman. ${ }^{20,21}$ Research has continually indicated that stress experienced by the mother during pregnancy is harmful to the baby's health and development. ${ }^{22,23}$ Whether this stress also influences the attachment bond between the mother and her unborn baby is the research question that the current study aims to answer.

Prior research has either studied MFA as a predictor of post natal parental stress, viewing stress as a response, or have studied the impact of prenatal distress on parent child relationship. ${ }^{24,25}$ The relationship between stress as a stimulus and maternal foetal attachment is yet to be explored. Thus the aim of the present study was to explore the relationship between perceived stress during pregnancy and maternal foetal attachment. It was hypothesised that higher stress levels will be associated with lower scores on MFA. As past literature has indicated that other psychological variables that are positively correlated with stress, such as anxiety and depression, have an inverse relationship with MFA, a similar relationship was assumed to exist between stress and maternal foetal attachment. ${ }^{15,17}$

\section{METHODS}

The present study had a correlational design with an exploratory nature. The sample consisted of 53 pregnant women who were contacted through an antenatal care clinic. The sample comprised of women with age ranging from 20 to 35 years (mean age $=26.4$ years). Most of the women were unemployed at the time of the study (92\%), had an educational qualification at the graduate level $(51 \%)$, belonged to a joint family system (87\%) and already had at least one child $(55 \%)$. In terms of the stage of pregnancy, $36 \%$ of the participants were in their first trimester, $28 \%$ were in their second trimester and $36 \%$ were in their third trimester of pregnancy at the time of the study. Only those women were included in the study who consented to participate in the study and who could read and answer to the questionnaire on their own. Two tools were used for the purpose of the present study.

Maternal foetal attachment scale by Cranley 7 - the scale originally consists of 24 items and is available in English language. The scale addresses five dimensions of maternal foetal attachment, namely:

- Differentiation of self

- Interaction with the foetus

- Attributing characteristics and intentions

- Giving of Self

- Role taking. 
The scale has been previously used on an Indian sample and has been validated for the same (Cronbach's reliability alpha $=0.71$ and Content Validity Index $=.78$ ). For the current study, MFAS was translated into Hindi language by the authors. Two items (item no. 3 and 4 of the differentiation of self from foetus subscale) were eliminated owing to the content being objectionable to be asked in an antenatal clinic as it might be considered hinting at sex determination which is prohibited in India. The two items were replaced by a single item 'I have decided on a name for my baby'. The scale is a Likert scale with answers ranging from 5- 'strongly agree' to 1'strongly disagree', with reverse scoring in one item (item no. 22).

The stress scale of the anxiety depression stress scale by Bhatnagar et al. ${ }^{26}$ This scale was used as the measure of stress. The scale consists of 14 items, with two response choices (yes or no). Agreement with an item receives a score of 1 and disagreement is scored as 0 . The higher the score on the scale, the higher is the stress level. Items of ADSS have been derived from previously validated stress measures such as, depression anxiety stress scale by Lovibond and Lovibond (1995), Stanford acute stress reaction questionnaire by Cardena, Koopman, Waelde and Spiegel (2000) and PTSD Checklist- Civilian (PCLC).

After briefly describing the purpose and procedure of the study to the participants, their verbal consent was obtained. The researcher collected the required demographic information and then handed over the two questionnaires to the participant. The questionnaires were administered to each participant on an individual level, in a quiet room. The participants were instructed to read each item carefully and respond honestly. There was no time limit to complete the questionnaires. The participants were assured that their responses would be kept confidential and used only for research purpose.

\section{Statistical analysis}

Scores of the participants on the two scales were correlated using the Pearson Product Moment method. The statistical analysis was carried out using the statistical package for social sciences software (version 20).

\section{RESULTS}

The product moment correlation procedure performed on the two sets of scores, on the maternal foetal attachment scale and those on the stress scale of the ADSS, yielded a correlation coefficient of $-0.55(\mathrm{p}<0.01)$. This correlation coefficient suggests that the relationship between the two variables, of maternal foetal attachment and stress during pregnancy, is of an inverse nature.

An $r$ of -0.55 indicates that this inverse relationship between maternal stress and MFA is of a moderate level, suggesting that in majority of the cases, higher the stress level, lower were the scores of MFA. This supports the hypothesis that higher stress levels would be associated with lower MFA scores. The exact nature of this relationship could better be understood by taking a closer look at the scores of the participants.

Table 1: Mean MFA scores of participants reporting different levels of stress.

\begin{tabular}{|llll|}
\hline Stress scores & $\begin{array}{l}\text { High } \\
(\mathbf{1 0 - 1 4})\end{array}$ & $\begin{array}{l}\text { Moderate } \\
(5-9)\end{array}$ & $\begin{array}{l}\text { Low } \\
(0-4)\end{array}$ \\
\hline $\begin{array}{l}\text { Mean scores on } \\
\text { MFA }\end{array}$ & 75.95 & 86.76 & 86.00 \\
\hline $\begin{array}{l}\text { Total no. of } \\
\text { participants }\end{array}$ & 25 & 17 & 11 \\
\hline
\end{tabular}

As can be seen in Table 1, those women who reported high scores on the stress scale scored considerably lower on the MFA scale as compared to the women who reported low or moderate levels of stress.

Analysis of the results in terms of the five subscales of the Maternal Foetal Attachment Scale allows for a deeper understanding of the relationship between stress and MFA.

Table 2: Correlation of stress scores with the five subscales of MFAS.

\begin{tabular}{|ll|}
\hline MIFA subscales & $\begin{array}{l}\text { Correlation with } \\
\text { stress }\end{array}$ \\
\hline Role taking & -.73 \\
\hline Differenciation from the foetus & -.49 \\
\hline Interaction with the foetus & -.56 \\
\hline Attribution of characteristics & -.23 \\
\hline Giving of self & -.74 \\
\hline
\end{tabular}

As can be seen in Table 2, all five subscales of MFAS show a negative correlation with stress, further supporting the hypothesis that higher the stress during pregnancy, lower will be the maternal foetal attachment. Individually, the two subscales of role taking and giving of self show the highest correlation coefficients (-.73 and -.74 respectively). The role taking subscale included items about the pregnant woman imagining herself in the maternal role and positively anticipating taking care of her baby. High correlation coefficient suggests that the more a woman is stressed during her pregnancy, the lesser she indulges in visualizations and thoughts about caring for the child when he or she is born.

The items in the giving of self subscale tap the expecting woman's feelings about the changes that the pregnancy has brought in her life and her attitudes about the sacrifices she has had to make due to her pregnancy. Thus, the results reveal that women who are less stressed during their pregnancy have more positive attitudes towards the changes, in terms of their lifestyle, physical 
appearance and health practices, which being pregnant has brought about.

The subscales of differentiation from the foetus and interaction with the foetus show moderate negative correlations with stress (-.49 and -.56 respectively). These subscales attempt to understand the extent to which the expecting mother thinks of the unborn foetus as a separate individual and how much she interacts with this individual through words and touch.

The subscale of attribution of characteristics shows a weak negative correlation with stress (-.23). This subscale is composed of items about the expecting woman's wonderment about the child's physical and psychological attributes.

\section{DISCUSSION}

The aim of the present research was to study the relationship between perceived stress during pregnancy and maternal foetal attachment among women. It was hypothesised that higher stress would be associated with lower MFA.

As the results in the previous section indicate, there exists a moderate inverse relationship between perceived stress during pregnancy and maternal foetal attachment $(r=-$ $0.55)$. These results are in keeping with results of previous studies which found maternal stress to be a predictor of prenatal attachment. ${ }^{27,28}$

Pregnancy has been found to be a state of comparatively high stress. ${ }^{29-31}$ Majorly, the stress experienced during pregnancy is eustress, arising out of the anticipation of the changing role that becoming a mother would bring and related to concern about the well-being of the baby. ${ }^{32}$ Such stress would not impede the formation of an attachment bond of the expecting mother with her unborn child, in fact it would facilitate it. It is when stress takes the form of distress, that it becomes a hindrance for maternal foetal attachment. ${ }^{28} \mathrm{~A}$ woman who experiences her pregnancy as an excessively stressful state, is likely to be preoccupied with worrisome thoughts and negative mood states. These would interfere in her indulging in thoughts and behaviour (e.g. talking to the baby in the womb, visualizing about caring for her baby after birth and doing activities that would enhance the unborn baby's well-being as well as her own) which form the foundation of the development of a positive attachment with the foetus.

Stress during pregnancy could arise from several factors such as worry about the child birth process, apprehension about the responsibility of a child, unplanned pregnancy, changing bodily appearance and worry about the changing role. ${ }^{25,33-36}$ Many of these factors directly relate to the maternal foetal attachment. For eg. The maternal foetal attachment scale by Cranly includes questions about the mother's attitude about her body image, the changes her pregnancy has brought in her life and what the woman had to give up for the health of the unborn child. As the results suggest, women who are highly stressed show low giving of self. This relationship probably takes such a shape because a woman who views her pregnancy as a negative experience, that has brought about unwanted changes in her appearance and lifestyle, would undergo more stress due to these inevitable changes. On the other hand, an expecting woman who has a stronger attachment to the unborn child and is positively anticipating the birth of this child would embrace the changes that come with pregnancy without any distress. ${ }^{32,37}$

Stress related to the parental role could also impede the development of an attachment bond between the mother and her unborn child as the experience of pregnancy gets associated with the negative stress state. Studies conducted on parental stress in mothers of young children have shown such a relationship between the parental stress and their attachment. ${ }^{38}$ Stress, therefore, not only emerges to be an important determinant of attachment between parents and their children, but also acts as an obstacle in the formation of the attachment bond in the prenatal stage.

Many of the factors that have been found to induce stress in expecting women, have also been reported to be associated with low prenatal attachment. Factors such as lack of social support, an unplanned pregnancy, marital problems, are all linked with lower MFA. ${ }^{39}$ Thus, it could be said that the presence of any of these factors during pregnancy adversely affects both MFA and stress.

It could also be said that women who have insecure attachment styles, who face discomfort in forming attachment bonds, might find the idea of becoming a mother stressful. Research conducted on mothers who report insecure attachment styles have found that these mothers are more likely to report higher parental stress. ${ }^{40,41}$ Thus, the inability to form an attachment to the child might serve as a predictor for stress during pregnancy.

The implications of the results of the current study are quite crucial. As the analyses of the subscales of MFA show, Women who experience low stress during their pregnancy, are likely to indulge in self giving behaviour for the betterment of the foetus's health and well being. Studies conducted on the birth outcomes of babies of stressed out mothers reveal that perceived stress during pregnancy predicts low birth weight and preterm birth. $^{42,43}$ Several studies have reported that expecting women with high stress are less likely to show healthy behaviour, such as normal sleep patterns, taking care of their oral and dental hygiene and take precautions for diseases. ${ }^{44-48}$ Thus, in addition to the direct negative effects stress has on the health of the child, stress also causes such adverse outcomes by reducing the mother's willingness to practice the required health behaviour. 
Highly stressed women also reported less frequent thoughts related to role taking, visualizations of the baby's characteristics and interacting with the foetus. Indulging in such cognitive activities have been closely linked with positive physical and psychological outcomes for the baby as well as the mother. ${ }^{49,50}$

Evidence backing the current results can be found in texts dating as back as the prehistoric era. According to the Ayurveda, the act of' Garbhsanskar', has strong and direct effects on the child's physical and mental functioning. Garbhsanskar includes special efforts taken to stimulate the baby's senses gently from outside for the maximum development of its physical and intellectual abilities. ${ }^{51}$ The ancient Hindu scriptures have recognized that the foetus, in the last few months of pregnancy, can listen to sounds that surround the mother and feel the mother's mood states. In fact, the kind of activities the mother indulges in, in her third trimester, have a direct effect on the child's intelligence and personality. The communication between the mother and her baby in the womb, with the mother speaking to the foetus and thinking about it and the foetus responding through movement, has also been linked with the bond that forms between the mother and her child. ${ }^{52}$ Considering that mothers who are stressed out during their pregnancy are less likely to interact with their foetus and think about it, babies of these mothers would be less likely to receive the benefits of Garbhsamskar.

Garbhsamskar has also been linked with reducing stress by working as a coping mechanism. ${ }^{51,53}$ Thus a vicious cycle emerges, with stress reducing the foetal communication and bonding, which in turn causes more stress. Studies have indicated that music listening during pregnancy, that calms the mother, is associated with lower levels of stress. ${ }^{54}$

From the ancient scriptures to the present day researches, emphasis has been laid upon a mother indulging in positive thoughts about her baby and the mothering role. Studies have indicated that positive thinking increases maternal interactions with the foetus and generally reduces stress. ${ }^{55}$ This is the relationship that has been seen in the present research, with mothers who reported lower stress levels, reporting a higher tendency to visualize a positive future in the mothering role. Thus, once again, not only does lower stress predict a stronger positive bond between the mother and her foetus, but imagining about the mothering role and thinking positively about the baby, which are linked with maternal foetal attachment, predict lower stress. Pregnancy being a highly stressful period could leave a woman vulnerable to the negative automatic thoughts, especially those related to worries regarding labour, delivery and the responsibility of a baby. In such a state, those women who develop a close and strong bond with their child, during pregnancy itself, would find the whole mothering process, from conception and even after birth, a much more pleasant experience.

\section{CONCLUSION}

In conclusion, the present study found that high stress during pregnancy could impede in a woman developing a strong attachment bond with the baby she is carrying. As a strong foetal attachment would mean the mother welcoming her child with love and positivity, ensuring a stress-free pregnancy seems to be the right step in terms of best practices for both the baby and the mother. These findings are significant for medical personnel as well as for family members of expecting women. Providing support, answering queries regarding pregnancy and parenthood, and psychological counselling, could all serve to reduce stress during this crucial phase in a woman's life, which would in turn facilitate the formation of maternal foetal attachment.

\section{ACKNOWLEDGMENTS}

Authors would like to thank Dr. S. K. Srivastava and Dr. Suneeta Srivastava for allowing the researchers to collect data for this study at their antenatal diagnostic centre.

\section{Funding: No funding sources \\ Conflict of interest: None declared \\ Ethical approval: Not required}

\section{REFERENCES}

1. Bowlby J. Attachment and loss: attachment. attachment and loss. New York: Basic Books; 1969:1.

2. Bowlby J. Attachment, communication, and the therapeutic process. A secure base: Parent-child attachment and healthy human development. 1988:137-157.

3. Stainton MC. Parent's Awareness of Their Unborn Infant in the Third Trimester. Birth. 1990;17:92-6.

4. Kennell JH, Slyter H, Klaus MH. The mourning response of parents to the death of a newborn infant. NEJM. 1970;283(7):344-9.

5. Klaus NH, Jerauld R, Kreger NC, McAlpine W, Steffa M, Kennell JH. Maternal attachment importance of the first post-partum days. NEJM. 1972;286:460-3.

6. Rubin R. Attainment of the maternal role. Nurs Res. 1967;16:129-37.

7. Cranley MS. Development of a tool for the measurement of maternal attachment during pregnancy. Nurs Res. 1981;30:281-4.

8. Condon JT, Corkindale C. The correlates of antenatal attachment in pregnant women. Br J Med Psychol. 1997;70:359-72.

9. Muller ME. The development and testing of the muller prenatal attachment inventory (Doctoral dissertation, University of California, San Francisco, 1989). Dissertation Abstracts Int. 1990:11.

10. Winnicott D. Collected Papers: Through Pediatrics to Psychoanalysis. New York: Basic Books. Primary maternal preoccupation;1956:301-302. 
11. Leckman JF, Feldman R, Swain JE, Eicher V, Thompson N, Mayes LC. Primary parental preoccupation: circuits, genes, and the crucial role of the environment. J Neural Trans. 2004;111(7):75371.

12. Leckman JF, Mayes LC, Feldman R, Evans DW, King RA, Cohen DJ. Early parental preoccupations and behaviors and their possible relationship to the symptoms of obsessive-compulsive disorder. Acta Psychiatrica Scandinavica Supplementum. 1999;396(100):1-26.

13. Siddiqui A, Hägglöf B. Does maternal prenatal attachment predict postnatal mother-infant interaction. Early Human Develop. 2000;59(1):1325.

14. Eswi A, Khalil A. Prenatal attachment and fetal health locus of control among low risk and high risk pregnant women. World Applied Sci. 2012;18(4):462-71.

15. Lindgren K. Relationships among maternal-fetal attachment, prenatal depression and health practices in pregnancy. Res Nurs Health. 2001;24:203-17.

16. Alhusen JL, Gross D, Hayat MJ, Woods AB, Sharps PW. The influence of maternal-fetal attachment and health practices on neonatal outcomes in lowincome, urban women. Res Nurs Health. 2012;35:112-20.

17. Hart R, McMahon CA. Mood state and psychological adjustment to pregnancy. Arch Women's Mental Health. 2006;9:329-37.

18. Zachariah R. Attachment, social support, life stress, and psychological well-being in pregnant lowincome women: a pilot study. Clin Excellence Nurse Practit. 2004;8(2):60-7.

19. Nagandla K, Nalliah S, Yin L, Majeed Z, Ismail M, Zubaidah S, et al. Prevalence and associated risk factors of depression, anxiety and stress in pregnancy. Int J Repro Contracept Obstet Gynecol. 2017;5(7):2380-8.

20. Nayak V, Ramaiah R, Praneetha. Pregnancy outcome in working women with work place stress. Int J Repro Contracept Obstet Gynecol. 2017;6(7):2891-6.

21. Vijayaselvi R, Beck MM, Abraham A, Kurian S, Regi A, Rebekah G. Risk factors for stress during antenatal period among pregnant women in tertiary care hospital of Southern India. J Clin Diagno Res. 2015;9(10):QC01-QC5.

22. Humenick SS, Howell OS. Perinatal experiences: the association of stress, childbearing, breastfeeding, and early mothering. J Perinat Educ. 2003;12(3):16-41.

23. Lobel M, Dunkel-Schetter C, Scrimshaw SC. Prenatal maternal stress and prematurity: a prospective study of socioeconomically disadvantaged women. Health Psychol. 1992;11(1):32-40.

24. Mazzeschi C, Pazzagli C, Radi G, Raspa V, Buratta L. Antecedents of maternal parenting stress: the role of attachment style, prenatal attachment, and dyadic adjustment in first-time mothers. Frontiers In Psychol. 2015.
25. Deater-Deckard K, Dodge KA, Bates JE, Pettit GS. Multiple risk factors in the development of externalizing behavior problems: group and individual differences. Dev. Psychopathol. 1998;10:469-93.

26. Bhatnagar P, Singh M, Pandey M, Sandhya, Amitabh. Manual for anxiety, depression and stress scale; Agra: National Psychological Corporation. 2011.

27. Karakoç H, Ozkanb H. The Relationship with prenatal attachment of psychosocial health status of pregnant women. Int J Health Sci. 2017;5(10).

28. Kwon MK, Bang KS. Relationship of prenatal stress and depression to maternal-fetal attachment and fetal growth]. J Korean Acad Nurs. 2011;2:276-83.

29. Woods SM, Melville JL, Guo Y, Fan MY, Gavin A. Psychosocial stress during pregnancy. Am J Obstet Gynecol. 2010;202(1):61.

30. Lobel M, Cannella DL, Graham JE, DeVincent C, Schneider J, Meyer BA. Pregnancy-specific stress, prenatal health behaviors, and birth outcomes. Health Psychol. 2008;27(5):604-15.

31. Wadhwa PD, Sandman CA, Porto M, DunkelSchetter C, Garite TJ. The association between prenatal stress and infant birth weight and gestational age at birth: a prospective investigation. Am J Obstet Gynecol. 1993;169(4):858-65.

32. Bondas T, Eriksson K. Women's lived experiences of pregnancy: a tapestry of joy and suffering. Qual Health Res. 2001;11(6):824-40.

33. Greer J, Lazenbatt A, Dunne L. 'Fear of childbirth' and ways of coping for pregnant women and their partners during the birthing process: a salutogenic analysis. Evidence Based Midwifery. 2014;12(3):95100.

34. Nelson J, O'Brien M. Does an unplanned pregnancy have long term implications for mother-child relationships? J Family Issues. 2012;33(4):506-26.

35. Hung CH, Lin CJ, Stocker J, Yu CY. Predictors of postpartum stress. J Clin Nurs. 2011;20:666-74.

36. Mercer RT. Becoming a mother versus maternal role attainment. J Nurs Scholarsh. 2004;36:226-32.

37. Armstrong T, Pooley JA. Being pregnant: a qualitative study of women's lived experience. J Prenatal Perinatal Psychol Health. 2004;20(1):4-24.

38. Jarvis PA, Creasey GL. Parental stress, coping, and attachment in families with an 18-month-old infant. Infant Behavior Develop. 1991;14(4):383-95.

39. Kaur S, Mamta, Sagar N. Comparative study to assess the maternal and paternal fetal attachment among the expectant mothers and fathers. Int J Repro Contracept Obstet Gynaecol. 2017;6(7):3134-7.

40. Saleem S, Qureshi N, Mahmood Z. Attachment, perceived social support and mental health problems in women with primary infertility. Int $\mathbf{J}$ Repro Contracept Obstet Gynaecol. 2019;8(6):2533-40.

41. Nygren M, Carstensen J, Ludvigsson J, Sepa A. Adult attachment and parenting stress among parents of toddlers. J Repro Infant Psychol. 2012;30(3):289302. 
42. DunkelSchetter C, Tanner L. Anxiety, depression and stress in pregnancy: implications for mothers, children, research, and practice. Curr Opin Psychiatry. 2012;25(2):141-8.

43. Staneva A, Bogossian F, Pritchard M, Wittkowski A. The effects of maternal depression, anxiety, and perceived stress during pregnancy on preterm birth: a systematic review. Women and Birth. 2015.

44. Ahmed AE, Albalawi AN, Alshehri AA, AlBlaihed RM, Alsalamah MA. Stress and its predictors in pregnant women: a study in Saudi Arabia. Psychol Res Behav Manag. 2017;10:97-102.

45. Goyal N, Singh S, Mathur A, Gupta N, Makkar D, Aggarwal V. Perceived stress among gravid and its effect on their oral health in Sri Ganganagar, Rajasthan, India. Int J Reprod Contra Obstet Gynecol. 2017;6(4):1381-7.

46. Kumar J, Samelson R. Oral health care during pregnancy and early childhood: practice guidelines. New York, NY: New York State Department of Health. 2006.

47. Laine MA. Effect of pregnancy on periodontal and dental health. Acta Odontol Scand. 2002;60(5):25764.

48. Kim EJ, Dimsdale JE. The effect of psychosocial stress on sleep: a review of polysomnographic evidence. Behav Sleep Med. 2007;5:256-78.

49. DiPietro JA. Psychological and psychophysiological considerations regarding the maternal-fetal relationship. Infant Child Dev. 2010;19(1):27-38.
50. El-Sayed H, El-Sayed M, Hassan SI, Hakeem SA, Aboud H, Ibrahim A. Effect of women self monitoring of fetal kicks on enhancing their general health status. Am J Nurs Res. 2018;6(3):117-24.

51. Deshpande J. The effect of selected aspect of garbhasanskar on stress, coping strategies and wellbeing of antenatal mothers. Int J Sci Res. 2016;5(3).

52. Tagi P. The science behind garbhsanskar. Discover India Sanskrit our culture our way of life. 2014.

53. Beddoe A, Paul Y. The effects of mindfulness-based yoga during pregnancy on maternal psychological and physical distress. 2009.

54. Hsing-Chi C, Chen-Hsiang Y, Shu-Yueh C, ChungHey C. The effects of music listening on psychosocial stress and maternal-fetal attachment during pregnancy. Complement Ther Med. 2015;23:509-15.

55. Foley S, Hughes C. Great expectations? Do mothers' and fathers' prenatal thoughts and feelings about the infant predict parent-infant interaction quality? A meta-analytic review. Develop Review. 2018;48:10.

Cite this article as: Srivastava A, Bhatnagar P. Maternal foetal attachment and perceived stress during pregnancy. Int J Reprod Contracept Obstet Gynecol 2019;8:3750-6. 